\title{
EKSPLORASI BUDAYA NTT DALAM NOVEL GERSON POYK
}

\author{
Imelda Oliva Wissang \\ Institut Keguruan dan Teknologi Larantuka \\ imeldaoliviawussang@gmail.com
}

\author{
Arsiya Wanaeloh \\ Muslim Education Development Association of Thailand \\ arsiyawan@gmail.com \\ Tobias Nggaruaka \\ Universitas Musamus \\ tobias@unmus.ac.id
}

\begin{abstract}
This article aims to describe the exploration of NTT's culture in the novels by Gerson Poyk as one of the national writers, Angkatan `66. This NTT-born author writes novel literary works by raising cultural traditions as a characteristic, the identity of the NTT people, cultural traditions with the values contained in them that are lived and preserved, although some have begun to disappear by the influence of modern culture. The uniqueness of Gerson Poyk is that he is able to raise the cultural background of NTT with its vast territory into his novels with a straightforward, expressive, and high aesthetic style of expression. Not only limited to cultural traditions but tourism development, agricultural cultivation, commercial crops, livestock, fisheries, handicrafts. Through a number of his novels, Gerson Poyk explores the culture that exists in the life of the people of NTT which can be used as a character of Indonesian culture. This research uses the theoretical basis of sociology of literature with the emphasis that the novel is actually a form of socio-historical embodiment, where novels can witness paintings of social and social reality. history, into a genre that is close to social phenomena. Using qualitative research methods in literature studies can describe, understand, and explain the exploration of NTT culture in the novel by Gerson Poyk. Exploration of NTT culture as a character of Indonesian culture in Gerson Poyk's novel, 1) exploring the cultural elements of the knowledge system towards the love of the NTT people to study, 2) exploring the cultural elements of the kinship and kinship system of the love of the NTT people to maintain relationships, 3) exploring the cultural elements of the system. livelihoods towards the love of the people of NTT doing work, 4) exploring the cultural elements of the religious system towards the love of the people of NTT in carrying out religious traditions, and 5) exploring elements of art culture towards the love of the people of NTT in the arts and culture.
\end{abstract}

Keywords: exploration, culture, novel

\begin{abstract}
ABSTRAK
Artikel ini bertujuan mendeskripsikan eksplorasi budaya NTT dalam novel-novel karya Gerson Poyk sebagai salah satu sastrawan nasional, Angkatan `66. Pengarang kelahiran NTT ini, menulis karya sastra novel dengan mengangkat tradisi budaya sebagai ciri khas, identitas masyarakat NTT, tradisi budaya dengan nilai-nilai yang terkandung di dalamnya yang dihidupi dan dilestarikan., meskipun ada yang sudah mulai hilang oleh pengaruh budaya moderen. Keunikan Gerson Poyk yakni mampu mengangkat latar budaya NTT dengan wilayahnya yang luas ke dalam karya novelnya dengan gaya pengungkapan yang lugas, ekspresif, berdaya estetika tinggi. Tidak hanya terbatas pada tradisi budaya tetapi pengembangan pariwisata, budidaya pertanian, tanaman perdagangan, perternakan, perikanan, kerajinan tangan. Melalui sejumah karya novelnya Gerson Poyk mengeksplorasi budaya yang ada dalam kehidupan masyarakat NTT yang dapat dijadikan salah satu karakter budaya Indonesia Penelitian ini menggunakan landasan teori sosiologi sastra dengan penekanan bahwa novel sesungguhnya merupakan bentuk perwujudan sosio-historis, dimana novel dapat menjadi saksi lukisan realitas sosial
\end{abstract}


dan sejarah, menjadi genre yang dekat dengan fenomena sosial. Dengan menggunakan metode penelitian kualitatif dalam kajian sastra dapat mendeskripsikan, memahami, dan menjelaskan ekspslorasi budaya NTT dalam novel karya Gerson Poyk. Eksplorasi budaya NTT sebagai karakter budaya Indonesia dalam karya novel Gerson Poyk yakni, 1) mengeksplorasi unsur budaya sistim pengetahuan terhadap kecintaan masyarakat NTT menuntut ilmu, 2) mengeksplorasi unsur budaya sistim kekeluargaan dan kekerabatan terhadap kecintaan masyarakat NTT menjaga relasi, 3) mengeksplorasi unsur budaya sistim mata pencaharian terhadap kecintaan masyarakat NTT menjalankan pekerjaan, 4) mengeksplorasi unsur budaya sistim religi terhadap kecintaan masyarakat NTT menjalankan tradisi keagamaan, dan 5) mengeksplorasi unsur budaya kesenian terhadap kecintaan masyarakat NTT dalam bidang seni, budaya.

Kata kunci : eksplorasi, budaya, novel

\section{PENDAHULUAN}

Karya sastra hadir di tengah masyarakat memberikan sumbangan gagasan, ide maupun refleksi, membangkitkan imaji dan kesadaran serta sebagai kontrol sosial terhadap berbagai problematika kehidupan. Sebagai sebuah karya seni, sastra mengungkapkan realitas kehidupan sosial maupun personal yang digambarkan pengarang dengan bahasa yang indah penuh makna. Sastra sebagai gambaran realitas kehidupan sosial merupakan bagian integral dari kebudayaan karena menggambarkan kehidupan masyarakat, mendeskripsikan pengalaman kemanusiaan yang terjadi di tengah masyarakat sebagaimana realita yang terjadi dalam kehidupan sosial masyarakat. Gambaran realitas sosial ini terungkap dalam karya-karya sastra, seperti novel, salah satu karya sastra yang mengisahkan kehidupan manusia dengan rangkaian peristiwa atau alur yang dikisahkan pengarang, pemanfaatan latar atau seting tertentu, munculnya tokoh cerita dengan watak yang ditampilkan serta berbagai unsur pembangun lainnya sebagai keutuhansebuah novel sehingga menjadi cerita yang menarik, berkesan, bermakna, dan memberikan pesan, nilai yang berguna bagi kehidupan.

Karya sastra, menurut (Djojosuroto, 2006) adalah refleksi pengarang tentang hidup dan kehidupan yang dipadu dengan gaya imajinasi dan kreasi yang didukung oleh pengalaman dan pengamatannya atas kehidupan tersebut. Sebuah karya sastra tidak dapat lepas dari situasi dan kondisi masyarakat pada saat sebuah karya sastra itu diciptakan.

Karya sastra dapat berupa puisi, cerpen, novel yang merupakan gambaran realitas kehidupan masing-masing memiliki karakteristiknya. Salah satu karya sastra sebagai gambaran realitas kehidupan yang memiliki kemiripan dengan fakta di dunia nyata adalah novel. Isi karya sastra novel dapat merupakan rekaman yang terinspirasi dari dunia nyata, dipadukan dengan pengalaman, dibahasakan pengarang dengan imajinasi yang kuat, memikat dengan pesanpesan dan kandungan nilai yang tinggi bagi pembaca (Sehandi, Y., \& Bala, 2021; Anggraini, 2019; Amriani.H, 2014). Gambaran realitas kehidupan tersebut ditemukan dalam sejumlah novel karya sastrawan Gerson Poyk, seperti novel Cumbuan Sabana, Tarian Ombak, Seribu Malam Sunyi, dan Enu Molas Di Lembah Lingko, novel-novel yang secara khusus merekam jejak kehidupan masyarakat NTT yang memiliki beragam keunikan sebagai ciri, identitas budaya masyarakat NTT.

Nama Gerson Poyk sudah dikenal luas di dunia sastra. Gerson Poyk, pengarang kelahiran NTT merupakan salah satu sastrawan nasional, angkatan `66, banyak menulis karya sastra novel dengan mengangkat tradisi budaya sebagai ciri khas, identitas masyarakat NTT. Tradisi budaya NTT dengan nilai-nilai yang terkandung di dalamnya merupakan tradisi yang dihidupi dan dilestarikan, meskipun ada yang sudah mulai hilang atau berubah oleh pengaruh budaya moderen. Realita yang digambarkan Gerson Poyk dalam novel-novelnya tidak hanya 
terbatas pada tradisi budaya tetapi juga kekhasan dalam pengembangan pariwisata, budidaya pertanian, tanaman perdagangan, perternakan, perikanan, kerajinan tangan. Melalui sejumah karya novelnya Gerson Poyk mengeksplorasi budaya yang ada dalam kehidupan masyarakat NTT dan budaya ini akan menjadi karakter budaya Indonesia.

Sebagai sastrawan besar, Gerson Poyk melalui karya novelnya sangat berperan dalam memperkenalkan, mengangkat dan mengeksplorasi budaya yang tersebar di berbagai wilayah NTT, karya novel yang mengandung nilai-nilai luhur kehidupan dalam berbagai kebiasaan, adat, tradisi dan berbagai pesona alam NTT, seperti kekhasan sistim pertanian, persawahan, misalnya lodok lingko dalam novel Enu Molas Di Lembah Lingko yang secara implisit mengandung makna, nilai serta karakter keadilan, kerja sama, persatuan sebagai kekuatan dalam masyarakat. Keunikan Gerson Poyk yakni mampu mengangkat latar budaya NTT dengan wilayahnya yang luas ke dalam karya novelnya dengan gaya pengungkapan yang lugas, ekspresif, berdaya estetika tinggi. Keunikan dan kekahsan ini menjadi pertimbangan peneliti untuk mengkaji sejumlah novelnya tentang eksplorasi budaya NTT dengan kekayaan nilai lokal yang menjadi karakter budaya Indonesia, dimana karakter budaya Indonesia sesungguhnya dibangun dari beragam karakter budaya Nusantara, seperti budaya NTT untuk merefleksikan dan memperkuat keindonesiaan.

Proses kreatif Gerson Poyk dimulai sejak tahun 1955 dimana secara terus-menerus berkarya, mengangkat citra Provinsi NTT ke dalam panggung sastra Indonesia modern melalui karya-karya yang dihasilkan, seperti puisi, cerita pendek, naskah drama, terutama penulisan novel. Selain itu menulis berbagai artikel sastra untuk dunia jurnalistik. Pembaca atau peneliti karya sastra dapat menghubungkan karya-karya sastra Gerson Poyk dengan kondisi alam lingkungan dan sosial budaya NTT. Karena karya sastra yang dihasilkan selalu berlatar budaya NTT, maka Gerson Poyk sering dijuluk pendongeng dari Timur (Sehandi, 2012).

Kecermatan Gerson Poyk dalam mengeksplorasi budaya NTT ke dalam karyanya dan keunikannya yang mampu mengangkat keragaman budaya NTT menjadi kisah cerita yang menarik dan bermakna, hal inilah yang membedakan Gerson Poyk dengan pengarang lain asal NTT. Melalui karya novelnya digambarkan budaya, tradisi, pesona alam dan berbagai kekhasan NTT dari berbagai daerah di NTT, bahkan ada warisan tradisi yang sudah kurang populer saat ini dalam kehidupan generasi muda NTT, tetapi ketika membaca dan memahami isi novel Gerson Poyk dapat membangkitkan kemauan untuk menelusuri realitas budaya yang ada sehingga dapat diperkenalkan kepada generasi muda secara kreatif melalui pembelajaran sastra inovatif dan literasi sastra sehingga menumbuhkan rasa cinta, bangga dan peduli dalam terhadap kekhasan budaya di NTT. Kekhasan budaya ini menurut (Sarong, 2013) sebagai keragaman budaya NTT dan menjadi warisan yang sangat mahal dan bernilai, sebagai kekuatan dan sumber pengetahuan bagi generasi bangsa ketika mempelajari NTT dengan daerah-daerah yang terbentang, suku, agama, tradisi, adat budaya seperti sistem pengetahuan dan sistem kekerabatan, sistem mata pencaharian, teknologi dan peralatan, religi, dan kesenian yang hidup di tengah masyarakat di setiap wilayah yang ada.

Dari uraian di atas, peneliti tertarik mengangkat permasalahan tentang eksplorasi budaya NTT dalam novel Gerson Poyk. Melalui penelitian ini diupayakan penelusuran, mengumpulkan data/informasi selengkap mungkin mengenai eksistensi novel Gerson Poyk dengan ciri khas budaya NTT.

Penelitian ini memiliki tujuan untuk mendeskripsikan eksplorasi budaya NTT dalam novel Gerson Poyk untuk menambah wawasan pengetahuan tentang budaya nasional yang dibangun dari budaya-budaya lokal, dan menjadi masukkan bagi para guru di sekolah 
khususnya di NTT dalam merancang pembelajaran sastra inovatif dan literasi sastra tentang pengarang, sastrawan dan tradisi budaya NTT dalam karya-karyanya.

\section{LANDASAN TEORI}

Karya sastra dapat menjelaskan realitas kehidupan masyarakat karena itu karya sastra, seperti novel memiliki keterlibatan atau implikasi sosial yang luas dalam kehidupan. Implikasi sosial karya sastra dapat dijelaskan melalui bidang sosiologi yang berusaha memahami semua aspek yang mempengaruhi kehidupan masyarakat, sehingga karya sasra tersebut memberikan manfaat bagi kehidupan masyarakat.

Penelitian ini menggunakan teori sosiologi sastra dimana gambaran atau rekaman realitas kehidupan masyarakat digambarkan secara imajinatif melalui karya seperti novel dengan estetika bahasa yang khas yang menarik minat pembaca. Endraswara (2011: 1) menjelaskan bahwa realitas kehidupan yang digambarkan dalam novel sesungguhnya merupakan bentuk perwujudan sosio-historis, dimana novel sebagai sebuah karya sastra menjadi saksi lukisan realitas sosial dan sejarah, dengan itu pula novel menjadi genre yang dekat dengan fenomena sosial.

Sosiologi sastra menurut (Ratna, 2003) merupakan penelitian terhadap karya sastra dengan mempertimbangkan keterlibatan struktur sosialnya, sehingga penelitian sosiologi sastra sebagai penelitian ilmiah dilakukan dengan tujuan mendeskripsikan, memahami, dan menjelaskan unsur-unsur karya sastra serta kaitannya dengan lingkungan sosial.

Beberapa kajian sosiologi sastra dalam novel yang relevan dengan penelitian ini dilakukan oleh (Novita, 2016) tentang Wujud dan Unsur Kebudayaan dalam Novel Kelir Slindet Karya Kedung Darma Romansha. Digambarkan melalui novel bahwa kebudayaan sebagai realitas kehidupan memberikan makna dan manfaat bagi kehidupan masyarakat. Kajian (Anggraini, 2019) tentang Peran Taufiq Ismail dalam Perkembangan Sastra di Indonesia, secara khusus mengeksplorasi kiprah Taufiq Ismalil dalam dunia satra melalui karya-karya yang dihasilkan yang bermanfaat bagi pengajaran sastra di sekolah dan bagi kehidupan masyarakat bangsa. Kajian (Amriani.H, 2014) tentang Realitas Sosial dalam Novel Ronggeng Dukuh Paruk, menjelaskan realitas dalam kehidupan masyarakat dengan berpangkal dari pemahaman bahwa sastra adalah cerminan kehidupan, sastra merupakan kristalisasi nilai dan pengalaman hidup sebagai kenyataan budaya. Kajian (Sehandi, Y., \& Bala, 2021) tentang Membaca Jejak Proses Kreatif Penyair NTT, John Dami Mukese. Dijelaskan bahwa puisi-puisi John Dami Mukese bertema religius yang berbasis pada masalah sosial sebagai realitas sosial yang tengah berlangsung dalam masyarakat Flores, NTT.

Karya sastra seperti novel berkaitan erat dengan dunia sosial dengan keanekaragaman yang ada, berelasi dengan aspek budaya sebagai cerminan kehidupan masyarakat. Ciri kehadiran novel sebagai gambaran sosial dengan mengetahui seberapa dekat realitas sosial dalam novel berhubungan dengan dunia sekitarnya, dan sejauh mana novelis memoles halus lingkungan sosial ke dalam estetika novel (Faruk.H.T, 2010 ; Endraswara. Suwardi, 2012: 2).

Realitas sosial sebagai gambaran kehidupan masyarakat merupakan unsur budaya yang saling berkaitan satu sama lain dan menjadi kekuatan, pedoman dalam hidup bermasyarakat, antara lain, a) penggunaan bahasa, b) sistim pengetahuan, c) sistem kekerabatan dan organisasi social, d) peralatan hidup dan teknologi, e) sistim mata pencaharian, f) sistim religi, dan g) kesenian, dimana unsur-unsur kebudayaan ini menjadi satu kesatuan yang membentuk suatu masyarakat atau bangsa berbudaya (Koentjaraningrat, 2005). 
Pengarang melalui karya novel menggambarkan realitas sosial masyarakat sebagai fenomena kehidupan sosial dan ini sekaligus menampilkan wajah budaya suatu masyarakat, sehingga novel menjadi karya yang sarat dengan kandungan makna serta nilai-nilai budaya yang dapat diwariskan dalam kehidupan terlebih kepada generasi penerus ( (Sehandi, Y., \& Bala, 2021; Novita, 2016; Amriani.H, 2014).

\section{METODE PENELITIAN}

Metode yang digunakan dalam penelitian ini, yakni metode deskripstif kualitatif. Pengumpulan data menggunakan teknik dokumentasi dengan cara kerja membaca, mencatat, mengidentifikasi, kodifikasi, validasi dan verifikasi (Creswell, 2009; Saldaña, 2011).

Penelitian kualitatif dalam kajian sastra, menurut (Endraswara , 2011) memiliki ciri penting, yakni bahwa penelitian dilakukan secara deskriptif, terurai dalam bentuk kata-kata atau gambar bukan bentuk angka; lebih mengutamakan proses baru diikuti hasil karena karya sastra merupakan fenomena yang membutuhkan penafsiran, dianalisis secara induktif untuk mengungkapkan makna.

Data dalam penelitian ini merupakan data tulis dari kutipan novel berupa kalimatkalimat, paragraf yang menggambarkan eksplorasi budaya NTT dalam novel Gerson Poyk. Sumber data penelitian ini dari empat novel karya Gerson Poyk. Novel (Gerson, 1979) Cumbuan Sabana. Ende:Nusa Indah. 1979, tebal 85 halaman, dalam penelitian ini disingkat (CS), Novel (Gerson, 2009) Tarian Ombak. Jakarta: Kakilangit. 2009, tebal 258 halaman, dalam penelitian ini disingkat (TO), Novel (Gerson, 2012) Seribu Malam Sunyi. Jakarta:Libri. 2012 tebal 324 halaman, dalam penelitian ini disingkat (SMS), dan Novel (Gerson, 2015) Enu Molas di Lembah Lingko. Jakarta: Q-Publisher. 2015, tebal 230 halaman, dalam penelitian ini disingkat (EMLL).

Data diperoleh melalui pembacaan berulang, diinterpretasi, dianalisis dan disajikan dalam bentuk uraian deskripsi serta disimpulkan berdasarkan fokus penelitian.

\section{TEMUAN DAN PEMBAHASAN}

Temuan data dalam penelitian ini berupa kutipan kalimat, paragraf dalam keempat novel karya Gerson Poyk Cumbuan Sabana (CS), Tarian Ombak (TO), Seribu Malam Sunyi (SMS), dan Enu Molas Di Lembah Lingko (EMLL) yang berkaitan dengan eksplorasi budaya NTT seperti berikut.

\section{Eksplorasi unsur budaya terhadap sistim pengetahuan}

Data-data yang ditemukan berkaitan dengan eskplorasi unsur budaya sistim pengetahuan dalam kutipan novel seperi berikut.

"Kami membangun tempat tinggal dari kayu-kayu setempat, daun kelapa, ijuk dan ilalang dijadikan atap rumah. Setelah rumah selesai dibangun, kami mencangkul tanah, membuat pagar, dan menanaminya. Lalu memelihara ternak. Sambil bertani dan beternak, kami membuat buletin profil desa, kecamatan dan kabupaten dengan mesin tik dan alat stensil butut. Tidak ketinggalan sebuah newsletter sederhana (TO. 2009: 141),

"Rumahnya dikelilingi oleh tanaman yang tumbuh subur. Kandang ayam agak tinggi. Kotoran ayam menjadi kompos untuk menyuburkan tanaman" (TO. 2009: 74). 
"Saya pingin tinggal di sini, membuka kebun kapas di sini, membuka kebun tarum di sini, menanam pohon-pohon berwarna untuk mengolah selimut ikat" (MSM. 2012:167).

2. Eksplorasi unsur budaya terhadap sistim kekeluargaan dan kekerabatan

Temuan data tentang eksplorasi unsur budaya sistim kekeluargaan dan kekerabatan dalam kutipan novel, seperti berikut.

"Di kampungku aku punya tunangan yang disediakan orangtuaku"

(SMS. 2012:31).

"Pesta perkawinan adat, tarian massal Rote, kabalai, diadakan selama seminggu. Begitu juga padoa Sabu-karena banyak famili. Mereka akan membawa lego-legosebuah tarian massal, melingkar lelaki dan perempuan bergandengan..." (CS, 1979: 66).

"Kalau habis pisang dan ubi atau jagung atau beras, tinggal mendarat saja di kampung-kampung nelayan dan menukar ikan dengan makanan lain."(TO.2009: 134).

3. Eksplorasi budaya terhadap sistim mata pencaharian

Data-data yang ditemukan berkaitan dengan eksplorasi unsur budaya sistim mata pencaharian, sebagai berikut.

"Buatlah rumah dari kayu-kayu hutan. Tinggallah sebagai petani, peternak, perajin, atau pedagang" (SMS. 2012: 9)

"Ia memikul jagung, beras, jeruk, dan ayam yang ditukar di desa-desa yang jauh di sana" (TO 2009: 167).

"Petani menggarap tanah dan pekerjaan lain, misalnya mengurus ternak dan mengolah tanah. Malah cara orang Manggarai mengolah tanah cukup efisien" (EMLL2009: 75).

\section{Eksplorasi budaya terhadap sistim religi}

Data-data berkaitan dengan eksplorasi unsur budaya sistim religi ditemukan dalam kutipan novel seperti berikut.

"Kesucian manusia terbatas. Hanya Tuhanlah yang kesuciannya tak terbatas." (EMLL. 2009: 57).

"Pertemuan tak terencanakan di tepi lapangan perintis Lekunik itu, merupakan rahmat dari Tuhan bagi Roki” (SMS. 2012: 167).

"Sesuai adat, setiap putra Rote yang pergi merantau, badannya pasti 
berlumuran dengan dosa. Ia harus mengikuti upacara save tasi oe"

(SMS. 2012: 157).

5. Eskplorasi budaya terhadap kesenian

Temuan data berkaitan dengan eksplorasi unsur budaya kesenian seperti pada kutipan novel berikut.

"Tiba-tiba muncul dua lelaki muda di atas kuda tunggang dengan memakai

Ti’i Langga" (SMS. 2012: 133).

"Dua puluh buah Sasando dari pulau Rote diborong untuk dikirim ke

museum-museum di luar negeri” (SMS. 2012: 186).

"Musik Sesando mengalun sendu ketika para tamu makan dan minum...gong dan tambur berbunyi. Nyanyian rakyat yang dimulai oleh manhelo atau penyair, disambut peserta kabalai. Syair dibawakan oleh manhelo dan peserta tarian" (CS. 2979: 75).

Temuan data penelitian di atas akan dilanjutkan dalam pembahasan yang menjelaskan eksplorasi budaya NTT dalam novel Gerson Poyk seperti berikut.

1. Eksplorasi unsur budaya sistim pengetahuan terhadap kecintaan masyarakat NTT menuntut ilmu

Unsur kebudayaan tentang sistim pengetahuan sangat berkaitan dengan pendidikan, lingkungan hidup atau ekologi untuk melakukan pengembangan, pengolahan lingkungan seperti, lahan pertanian, peternakan, maupun budi daya lainnya sebagai wujud pengembangan terhadap alam dengan memanfaatkan pengetahuan local dipadu dengan sistem pengetahuan dan teknologi yang berkembang dengan tetap mempertahankan kekhasan NTT sebagai identitas masyarakat.

Dalam eksplorasi budaya sistim pengetahuan terungkap rasa bangga, peduli, tanggung jawab atas alam lingkungan untuk diolah, dikembangkan, dilestarikan demi kepentingan bersama dengan memanfaatkan pengetahuan, teknologi, dan pendidikan untuk mendukung pengembangan yang berguna bagi kepentingan bersama tanpa meninggalkan kebiasaankebiasaan yang sudah menjadi tradisi setempat, seperti digambarkan dalam kutipan novel "Kami membangun tempat tinggal dari kayu-kayu setempat, daun kelapa, ijuk dan ilalang dijadikan atap rumah. Setelah rumah selesai dibangun, kami mencangkul tanah, membuat pagar, dan menanaminya. Lalu memelihara ternak. Sambil bertani dan beternak, kami membuat buletin profil desa, kecamatan dan kabupaten dengan mesin tik dan alat stensil butut. Tidak ketinggalan sebuah newsletter sederhana (TO. 2009: 141), Berbekal pengetahuan yang ada ternyata dapat dikembangkan menjadi lebih produktif terlebih mengolah lahan, menatanya sambil mengikuti perkembangan dan kemajuan ilmu pengetahuan, seperti digambarkan dalam kutipan novel "Rumahnya dikelilingi oleh tanaman yang tumbuh subur. Kandang ayam agak tinggi. Kotoran ayam menjadi kompos untuk menyuburkan tanaman" (TO. 2009: 74).

Selain itu kecintaan masyarakat NTT dalam menuntut ilmu selalu diikuti rasa tanggung jawab untuk merintis usaha baru dari apa yang ada sehingga pelestarian terhadap warisan 
tradisi yang ada tetap terjaga, seperti terungkap dalam kutipan novel "Saya pingin tinggal di sini, membuka kebun kapas di sini, membuka kebun tarum di sini, menanam pohon-pohon berwarna untuk mengolah selimut ikat" (MSM. 2012:167).

2. Eksplorasi unsur budaya sistim kekeluargaan dan kekerabatan terhadap kecintaan masyarakat NTT menjaga relasi

Unsur kebudayaan tentang sistim kekeluargaan dan kekerabatan dalam masyarakat berkaitan dengan budaya hidup sosial masyarakat NTT dimana adanya saling menghargai, saling menerima, saling mengakui, saling membantu serta kokohnya persatuan, kerukunan, solidaritas, keharmonisan, ketulusan karena saling percaya di antara warga.

Budaya sistim kekeluargaan dan kekerabatan ini sebagaimana digambarkan dalam novel berkaitan dengan adat istiadat hubungan kekeluargaan dalam perkawinan agar ikatan kekeluargaan tetap terjalin, dan sistim kekerabatan tetap terjaga, seperti dalam kutipan novel "Di kampungku aku punya tunangan yang disediakan orangtuaku" (SMS. 2012:31).

Budaya sistim kekeluargaan dan kekerabatan dalam kehidupan masyarakat NTT dapat ditemukan ketika berkumpul bersama merayakan pesta adat dimana setiap orang ikut terlibat, mengambil bagian dalam pelaksanaan pesta, seperti menyanyi dan menari adat, seperti terungkap dalam kutipan novel "Pesta perkawinan adat. Tarian massal Rote, kabalai, diadakan selama seminggu. Begitu juga padoa Sabu-karena banyak famili. Mereka akan membawa legolego-sebuah tarian massal, melingkar lelaki dan perempuan bergandengan" (CS, 1979: 66).

Budaya kekeluargaan dan kekerabatan dalam kehidupan masyarakat NTT sering disertai kebiasaan berbagi dimana secara leluasa memberi, membantu, menerima, menghargai diantara warga, seperti terungkap dalam kutipan novel "Kalau habis pisang dan ubi atau jagung atau beras, tinggal mendarat saja di kampung-kampung nelayan dan menukar ikan dengan makanan lain"(TO.2009: 134).

3. Eksplorasi budaya sistim mata pencaharian terhadap kecintaan masyarakat NTT menjalankan pekerjaan

Unsur kebudayaan tentang sistim mata pencaharian berkaitan dengan kehidupan ekonomi masyarakat dengan menjalankan berbagai usaha sebagai petani, nelayan, peternak atau pengrajin lainnya yang terus mengembangkan budidaya pertanian, perikanan, peternakan, tenun ikat atau pengembangan wisata. Dalam mengembangkan unsur budaya ini selalu disertai ketekunan, perjuangan, semangat pengorbanan, semangat gotong royong, tanggung jawab, ketulusan, rasa bangga serta keterbukaan terhadap sesuatu yang baru dari perkembangan ilmu pengetahuan dan teknologi meski diterapkan secara sederhana sesuai situasi dan keadaan setempat, seperti kutipan: "Buatlah rumah dari kayu-kayu hutan. Tinggallah sebagai petani, peternak, perajin, atau pedagang" (SMS. 2012: 9)

Kecintaan masyarakat NTT dalam melaksanakan pekerjaan, seperti sebagai petani tradisional menggambarkan rasa bangga, rasa memiliki, percaya diri, memiliki kemauan yang kuat, ketekunan, semangat, kerja keras, kerja sama, berjuang dan berusaha sampai mendapatkan hasil yang memuaskan baik bagi diri tetapi terlebih bagi masyarakat luas. Kecintaan ini sekaligus merupakan identitas masyarakat NTT yang berani berjuangm bekerja yang halal dan menghasilkan sehingga setelah bekerja keras pasti akan mendapat hasil yang dapat membiayai hidup, membantu keluarga, membantu sesama yang membutuhkan, berbagi 
dan ikhlas memberi, seperti kutipan "Ia memikul jagung, beras, jeruk, dan ayam yang ditukar di desa-desa yang jauh di sana" (TO 2009: 167).

Semangat pengorbanan dan kemauan yang kuat untuk mengembangan budidaya pertanian menjadi ciri khas masyarakat NTT yang masih bekerja secara tradisional dengan memperhitungkan kalender tradisional sesuai musim. Semangat pengorbanan, tekun berusaha, berani berkorban, berjuang dan berinisiatif mencari pekerjaan tambahan serta mengembangkannya untuk menambah penghasilan bagi keluarga, membantu sesama digambarkan dalam kutipan novel, "Petani menggarap tanah dan pekerjaan lain, misalnya mengurus ternak dan mengolah tanah. Malah cara orang Manggarai mengolah tanah cukup efisien" (EMLL2009: 75).

4. Eksplorasi budaya sistim religi terhadap kecintaan masyarakat NTT menjalankan tradisi keagamaan

Unsur kebudayaan berkaitan dengan sistim religi dalam kehidupan masyarakat NTT menggambarkan ketaatan dan kesetiaan, ketekunan untuk menjalankan tradisi keagamaan, dan berbagai ritual serta kebiasaan hidup beragama yang didasarkan pada iman dan keyakinan pada Tuhan Sang Pencipta. Kesadaran akan keterbatasan sebagai manusia dan menimani kemahakuasaan Tuhan, serta kepercayaan terhadap pemeliharaan leluhur menjadi kekuatan dalam membangun hidup religi diantara warga. Kehidupan religi yang kuat serta ketekunan menjalankannya dapat menciptakan iklim toleransi antara umat beragama, kerukunan, kerja sama, saling menghargai satu sama lain dan nilai-nilai ini menjadi modal dan kekuatan yang tangguh dalam hidup bermasyarakat.

Kecintaan menjakankan tradisi keagamaan ini terungkap dalam saling mengasihi, ikhlas, mengamalkan persaudaraan lintas batas, selalu mawas diri terhadap hal-hal yang mersak persaudaraan, selalu sadar dan tahu diri sehingga kerukunan dan religisiotas warga selalu menumbuhkan kesadaran bahwa seluruh kehidupan ini merupakan anugerah Tuhan dengan kebaikanNya yang tak terbatas, seperti dalam kutipan novel, "Kesucian manusia terbatas. Hanya Tuhanlah yang kesuciannya tak terbatas" (EMLL. 2009: 57).

Kesadaran akan penyertaan Tuhan dalam perjuangan hidup merupakan budaya hidup beragama yang tetap ada dalam kehidupan masyarakat NTT, seperti digambarkan dalam kutipan novel, "Pertemuan tak terencanakan di tepi lapangan perintis Lekunik itu, merupakan rahmat dari Tuhan bagi Roki” (SMS. 2012: 167).

Kecintaan terhadap hidup religi juga selalu berkaitan dengan tradisi yang dijalankan secara turun temurun dengan menyadari keterbatasan diri, mengakui setiap kesalahan atau pelanggaran maupun dosa yang dapat merusak keharmonisan hidup masyarakat. Terhadap kesalahan atau pelanggaran yang dilakukan selalu diadakan pembersihan secara adat terlebih dahulu sehingga tercipta keharmonisan, kedamaian, seperti terungkap dalam kutipan novel "Sesuai adat, setiap putra Rote yang pergi merantau, badannya pasti berlumuran dengan dosa. Ia harus mengikuti upacara save tasi oe" (SMS. 2012: 157).

5. Eskplorasi budaya kesenianterhadap kecintaan masyarakat NTT dalam bidang seni, budaya

Budaya kesenian merupakan warisan yang memperkenalkan kekhasan tradisi seni yang ada di masyarakat sepeti, tarian, lagu, musik tradisional juga kekhasan bangunan rumah adat, 
adanya ritual dan berbagai upacara adat, syair atau pantun adat, hingga kerajinan tenun ikat dan kerajinan tangan lainnya dengan motif khas mengandung nilai estetik yang menggambarkan ciri, identitas, keunikan masyarakat NTT.

Budaya kesenian ini, seperti topi Ti'i Langga, topi khas dari pulau Timor selain menjadi kebanggaan juga sebagai simbol kebesaran, kehormatan, penghargaan, penerimaan serta pengakuan, seperti dalam kutipan novel "Tiba-tiba muncul dua lelaki muda di atas kuda tunggang dengan memakai Ti'i Langga" (SMS. 2012: 133).

Kecintaan terhadap warisan budaya menggambarkan rasa bangga dan rasa memiliki terhadap produk lokal, seperti topi tradisional yang merupakan keunikan, ciri khas masyarakat NTT apalagi ketika produk tersebut diperkenalkan, dipasarkan hingga ke luar negeri, seperti dalam kutipan novel "Dua puluh buah Sasando dari pulau Rote diborong untuk dikirim ke museum-museum di luar negeri” (SMS. 2012: 186).

Kecintaan terhadap kesenian tradisional terungkap juga dalam pesta adat yang diselenggarakan bersama seluruh warga dengan diiringi musik tradisional, seperti musik Sesando sambil mementaskan tarian dan membawakan syair serta pantun adat. Keunikan budaya kesenian ini memiliki warisan nilai luhur yang menyadarkan masyarakat akan tingginya nilai persatuan, kekeluargaan, perdamaian, saling menghargai diantara warga, seperti kutipan novel "Musik Sesando mengalun sendu ketika para tamu makan dan minum...gong dan tambur berbunyi. Nyanyian rakyat yang dimulai oleh manhelo atau penyair, disambut peserta kabalai. Syair dibawakan oleh manhelo dan peserta tarian” (CS. 2979: 75).

\section{PENUTUP}

Gerson Poyk, salah satu putra NTT dikenal sebagai sastrawan nasional angkatan `66. Pengarang kelahiran NTT ini menulis karya sastra novel dengan mengangkat tradisi budaya dari tiap daerah sebagai ciri khas, identitas masyarakat NTT. Tradisi budaya yang diperkenalkan ini mengandung nilai-nilai yang dihidupi, dijaga dan dilestarikan, meskipun ada yang sudah mulai hilang oleh pengaruh budaya moderen. Melalui sejumah karya novelnya Gerson Poyk mengeksplorasi nilai-nilai budaya yang ada dalam kehidupan masyarakat NTT dimana nilai budaya ini merupakan karakter budaya Indonesia.

Keunikan Gerson Poyk dalam karya novelnya yakni mampu mengangkat latar budaya NTT dengan sebaran wilayahnya yang luas dan beragam sehingga kekhasan setiap daerah atau wilayah terungkap. Gaya penceritaan yang lugas, ekspresif, berdaya estetika tinggi dapat menghantar pembaca untuk memahami, mengetahaui berbagai keunikan yang ada di NTT dan keunikan ini sebagai ciri, identintas masyarakat NTT. Eksplorasi budaya NTT dalam karya novel Gerson Poyk merupakan gambaran karakter budaya Indonesia yang beranekaragam, sebagaimana kenyataan bahwa karakter budaya Indonesia sesungguhnya dibangun dari beragam karakter budaya Nusantara, salah satunya budaya NTT.

Eksplorasi budaya NTT dalam novel karya Gerson Poyk sebagai karakter budaya Indonesia dapat digambarkan sebagai berikut 1) mengeksplorasi unsur budaya sistim pengetahuan terhadap kecintaan masyarakat NTT menuntut ilmu, 2) mengeksplorasi unsur budaya sistim kekeluargaan dan kekerabatan terhadap kecintaan masyarakat NTT menjaga relasi, 3) mengeksplorasi unsur budaya sistim mata pencaharian terhadap kecintaan masyarakat NTT menjalankan pekerjaan, 4) mengeksplorasi unsur budaya sistim religi terhadap kecintaan masyarakat NTT menjalankan tradisi keagamaan, dan 5) mengeksplorasi unsur budaya kesenian terhadap kecintaan masyarakat NTT dalam bidang seni, budaya. 


\section{DAFTAR PUSTAKA}

Amriani.H. 2014. Realitas Sosial Dalam Novel Ronggeng Dukuh Paruk Karya Ahmad

Tohari.sawerigading.kemdikbud.go.id/index.php/sawerigading/article/view/2Vol. 20, 1 April 2014: 99-108. Garuda - Garba Rujukan Digital （ristekbrin.go.id).

Anggraini, Nori. 2019. Peran Taufi Ismail dalam Perkembangan Sastra di Indonesia. Jurnal Lingua Rima: Jurnal Pendidikan Program Studi Bahasa dan Sastra Indonesia Vol. 8 No. 1 Januari 2019.

Creswell, John W. 2009. Research Design Quantitative, Qualitative, and Mixed

Methods Approaches. Kalifornia: SAGE Publications. Ins.

Endraswara, Suwardi. 2012. Teori Pengkajian Sosiologi Sastra Yogyakarta: UNY Press.

Endraswara, Suwardi. 2011. Metodologi Penelitian Sastra; Epistemologi, Model,

Teori, dan Aplikasi. Yogyakarta: CAPS.

Djojosuroto, Kinayati. 2006. Analisis Teks Sastra dan Pengajarannya. $\quad$ Yogyakarta: Pustaka.

Faruk, H.T. 2010. Pengantar Sosiologi Sastra: Dari Strukturalisme Genetik Sampai PosModernisme. Yogyakarta: Pustaka Pelajar.

Koentjaraningrat. 2005. Pengantar Antropologi. Bandung: Rineka Cipta.

Poyk, Gerson 1979. Cumbuan Sabana. Ende:Nusa Indah.

Poyk, Gerson 2009. Tarian Ombak. Jakarta:Kakilangit.

Poyk, Gerson 2012. Seribu Malam Sunyi. Jakarta:Libri.

Poyk, Gerson 2015. Enu Molas di Lembah Lingko. Jakarta: Q Publisher.

Saldaña, Johnny. 2011. Fundamentals of Qualitative Research. Oxford: Oxford University Press, Inc.

Sarong, Frans. 2013. Serpihan Budaya NTT. Maumere: Ledalero.

Sehandi, Y., \& Bala, A. 2021. Membaca Jejak Proses Kreatif Penyair NTT, John Dami Mukese. Jurnal Diglosia Volume 4 No 1, 2021. Hal 23-36.

https://doi.org/10.30872/diglosia.v4i1.88.

Sehandi, Yohanes. 2012. Mengenal Sastra dan Sastrawan NTT.

Yogyakarta:Penerbit Universitas Sanata Dharma.

Wijayanti, Novita. 2016. Wujud dan Unsur Kebudayaan dalam Novel Kelir

Slindet karya Kedung Darma Romnasha. 
JURNAL ILMIAH BAHASA DAN SASTRA

Volume 8 Nomor 1 Tahun 2021

eISSN : 25494155 - pISSN : 23557083

http://repository.ump.ac.id/3390/NOVITAWIJAYANTI. Akses 6-

12-219. 